Revista Iberoamericana, Vol. LXXI, Núm. 212, Julio-Septiembre 2005, 775-800

\title{
CUERPOS DE CUBA: \\ ALEGORÍAS DE CUBA A TRAVÉS DEL CUERPO FEMENINO EN LA NARRATIVA CUBANOAMERICANA
}

\author{
POR \\ Laura P. Alonso Gallo
}

Universidad de Huelva

\author{
¿Mi tierra? \\ Mi tierra eres tú. \\ ¿Mi gente? \\ Mi gente eres tú. \\ El destierro y la muerte \\ Para mí están adonde \\ No estés tú. \\ ¿Y mi vida? \\ Dime, mi vida, \\ ¿Qué es, si no eres tú? \\ Luis Cernuda, de Poemas para un cuerpo \\ Coronada de palmas \\ como una diosa recién llegada, \\ ella trae la palabra inédita, \\ el anca fuerte, \\ la voz, el diente, la mañana y el salto. \\ Nicolás Guillén, de "Mujer nueva" \\ "Un hombre con su amor" \\ Si todo fuera dicho \\ Y entre tú y yo la cuenta \\ Se saldara, aún tendría \\ Con tu cuerpo una deuda. \\ Luis Cernuda, de Poemas para un cuerpo
}

El concepto de patria ha dado lugar a una larga tradición de representaciones en diversas formas artísticas, como la pintura, la escultura, la música y la literatura. Directamente relacionada con los conceptos de tierra y nación, cuya innegable simbología de lo femenino ha alimentado la imaginación de los artistas, la patria ha sido representada 
de antiguo por una figura de mujer. ${ }^{1}$ En la tradición hispánica, además, debido a la sacralización de su natural fertilidad y protección de la prole, se le ha otorgado la característica de madre, de modo que hallamos una rica variedad de textos en los que se personifica a la patria con tal función femenina. ${ }^{2}$ La hermosura de la madre, desde la subjetividad masculina, radica en el amor, fidelidad y protección incondicionales a los hijos. La maternidad es un misterio para el hombre, acaso el único componente femenino ante el cual se siente espiritualmente inferior. La personificación artística de la patria como madre, por lo tanto, implica una relación filial que el varón honra con gratitud.

Muchos textos de la literatura cubanoamericana, ${ }^{3}$ con su característica "conciencia de exilio", ${ }^{4}$ parecen poner en tela de juicio la condición de la patria como madre leal. La encarnación de la idea de Cuba en figuras femeninas permite a los escritores explorar esa relación filial y transgredir las tradicionales leyes de respeto y devoción por la madre, rompiendo así su romántico misterio. Al igual que la patria se ha fragmentado en la diáspora, la madre pierde su carácter sagrado y eterno, haciéndose secular y mortal en los papeles humanos de madre, esposa e hija. Su cuerpo es para estos escritores un lugar de

\footnotetext{
${ }^{1}$ Ya en la literatura clásica latina, donde se empleaba la personificación como figura retórica de intenso valor poético y patético, aparece la patria como figura femenina en el primero de los Discurso contra Catilina de Cicerón, y más tarde en la Farsalia de Lucano, donde la patria se le aparece a César como una mujer triste, doliente, envejecida y hablando con autoridad al futuro emperador. La exaltación del sentimiento nacionalista durante el siglo xviI y muy especialmente el xix, que además incorporó el sentimiento romántico, brindó a los artistas de occidente la ocasión de personificar a la patria en sus poemas y pinturas; grandes músicos honraron también a la patria en sus composiciones, como Smetana, Sibelius y Tchaikovsky, remontándonos al siglo xx. En el mundo hispánico la tradición literaria de personificar a España es notable desde el propio Cervantes, y ya en siglos más recientes, la hallamos, por ejemplo en textos de miembros de las generaciones del 98 y del 27; en la América Latina es asimismo abundante, sobre todo en los tiempos de lucha independentista y de búsqueda de identidad nacional.

${ }^{2}$ Dicha personificación de la patria como madre no es exclusiva de la tradición hispánica, ni tampoco de un periodo histórico antiguo. En la introducción de Nationalisms and Sexualities (Routledge 1992) las editoras ponen de ejemplo el libro The Rape of Kuwait, cuyo éxito editorial durante la Guerra del Golfo demuestra que la exaltación nacionalista de siglos anteriores sigue vigente en nuestros días y que el discurso de la nación continúa empleando un sistema de valores masculino por el cual la patria se imagina como hembra característicamente "chaste, dutiful, daughterly or maternal” (6). En dicha colección de ensayos, presentada por Parker, Russo, Sommer y Yaeger, se analizan muchos textos literarios que obedecen a una visión del nacionalismo que George Mosse y Benedict Anderson conciben como "a distinctly form of male bonding" (6). Véase también Scattered Hegemonies. Postmodernity and Transnational Feminist Practices (Inderpal Grewal and Caren Kaplan, eds.), especialmente los ensayos de Lydia Liu (37-62), Mary Layoun (63-75) y Nalini Natarajan (76-89), que analizan la cuestión del cuerpo femenino y el discurso nacional en textos de diversas tradiciones literarias.

${ }^{3}$ A sabiendas de que es esencialista y redundante, sólo por razones prácticas adopto la denominación "cubanoamericano" o "cubanoamericana," empleada en general por la crítica, para designar tanto a los cubanos nacidos en la isla que se hallan en el exilio en los Estados Unidos, como a los descendientes de exiliados o emigrantes cubanos que ya han nacido en este país.

${ }^{4}$ Carolina Hospital asigna lo que denomina "conciencia de exilio" a todos los miembros del grupo que llamamos cubanoamericano, incluso a aquellos nacidos fuera de la isla (113).
} 
búsqueda donde poder establecer los límites de la patria en su experiencia de exilio; es la mirada a la madre con los ojos del hijo apartado de su seno.

En las obras narrativas de los escritores exiliados cubanos de la llamada "generación del uno y medio", como lo es Gustavo Pérez Firmat, ${ }^{5}$ y de los hijos de emigrantes que salieron de Cuba antes de la revolución de 1959, como Oscar Hijuelos, la isla de Cuba se presenta como dolorosa pérdida, espacio imaginario o memoria heredada. Pérdida, espacio y memoria se materializan, de modo directo o indirecto, en diversas geografías del cuerpo de los personajes femeninos creados por estos dos escritores. Así, Cuba puede verse representada en forma de mujer, personificada en los papeles de madre (abnegada, posesiva o rebelde), esposa (devota, infiel o desequilibrada) e hija (sumisa, irrespetuosa o indómita), cuya adhesión a las convenciones del género femenino o rechazo de las mismas, revelan diversas concepciones de la patria perdida.

Puesto que la noción de patria aparece marcada a priori por la pertenencia a una generación en concreto, así como por su carácter de exiliado o emigrante, el discurso literario se ve enriquecido con la experiencia de cada escritor. Para el exiliado de la generación del uno y medio, como Gustavo Pérez Firmat, la idea de patria se halla forjada por vivencias personales y, además, por la propia idea de patria que le ha inculcado a través de relatos la primera generación de exiliados (por ejemplo, sus padres). Por otra parte, habría que distinguir entre los miembros de la segunda generación que son hijos de exiliados y aquellos que son hijos de emigrantes. En ambos grupos, con mayor o menor intensidad, Cuba es la patria imaginada según los comentarios e historias de sus mayores. Sin embargo, para los primeros la noción de patria se alimenta de ciertos elementos ideológicos inseparables de la experiencia del exilio político, mientras que para los hijos de emigrantes nacidos en suelo estadounidense, como es el caso de Oscar Hijuelos, otros elementos de tipo socioeconómico influyen asimismo en su concepción de la patria. Sin menoscabo de dichas particularidades, debemos insistir en la gran diversidad de casos dentro de la diáspora cubana, donde, según afirma O’Reilly Herrera “no single response to, or definition of, ethnicity, culture or exile exists [no existe ninguna respuesta singular, o definición de etnicidad, cultura o exilio]”. Al igual que otras comunidades desplazadas de sus lugares geográficos de origen, la identidad cubana de la diáspora no es un concepto fijo. Es, en palabras de la crítica, “complex, contradictory, protean and provisional, for what is to be Cuban, to be Cuban-American, to be in exile is constantly being displaced

\footnotetext{
${ }^{5}$ El sociólogo Rubén Rumbaut designa a la generación intermedia de cubanos que nacieron en la isla pero se criaron y crecieron en Estados Unidos con el término “Generación del uno y medio”. Pérez Firmat se reconoce en la diferencia que otorga Rumbaut a esos jóvenes refugiados, que por fuerza se enfrentan a una doble transición, "two crisis-producing and identity-defining transitions: (1) adolescence and the task of managing the transition from childhood to adulthood, and (2) acculturation and the task of managing the transition from one sociocultural environment to another”. Haciéndose eco de la teoría de Rumbaut, Pérez Firmat lo cita en su trabajo Life on the Hyphen para explicar la peculiar condición de exiliados que posee su grupo generacional. Según Rumbaut, los miembros de la generación del uno y medio "form a distinctive cohort in that in many ways they are marginal to both the old and the new worlds, and are fully part of neither of them". Citado por Pérez Firmat en Life on the Hyphen. The Cuban-American Way, 4. Véase Rubén G. Rumbaut, "The Agony of Exile: A Study of the Migration and Adaptation of Indochinese Refugee Adults and Children".
} 
and re-negotiated [compleja, contradictoria, prótea y provisional, ya que ser cubano, ser cubanoamericano, estar en exilio, es algo que constantemente se desplaza y renegocia]" (93).

Para analizar esas diversas concepciones de la patria perdida he restringido mi estudio, dentro de la narrativa cubanoamericana, a la penúltima novela de Oscar Hijuelos The Empress of the Splendid Season (1999) y a la novela de Pérez Firmat Anything But Love (2000). En estas obras el cuerpo de los principales personajes femeninos se describe sensual, voluptuoso, prostituido, violado, enfermo, objeto de violencia masculina, asexuado o poco deseable. Todas estas características pueden interpretarse como expresiones simbólicas, positivas o negativas, de Cuba desde la perspectiva del exilio político y cultural. Cuba puede verse representada en los textos mencionados por un cuerpo de mujer. Todas estas mujeres son hijas, y algunas son madres y esposas o compañeras. Las características que conforman estos papeles femeninos se ven alteradas en su mayoría puesto que en las novelas hay, bien una revisión, bien una subversión de los roles tradicionales relativos al género femenino.

Este último caso, el de la subversión, puede entenderse como una reacción a los papeles tradicionales asignados a la hembra -madre, hija y esposa ejemplares en su sumisión y devoción a los hijos, a los padres y familia en general, y al esposo. Dicho fenómeno parece ser producto de la exploración que hacen los escritores de los arquetipos femeninos inscritos en una cultura dada, en este caso la cultura hispánica. El carácter psicológico que estos escritores otorgan a sus personajes femeninos (con desviaciones o sometimiento de sus supuestos papeles) puede interpretarse desde el punto de vista psicoanalista, feminista, o desde un filtro ideológico poscolonial por el cual los parámetros de raza, clase y nación se analizan según la ideología del “colonizado” cultural o políticamente. Según tales parámetros la mujer sometida al patriarcado cultural hispánico y la Cuba colonizada por el imperialismo estadounidense o por el comunismo castrista, donde la propia Cuba se halla representada por la segunda y tercera generación de mujeres exiliadas, contribuye o se resiste a tal colonización. Existe en los textos de los dos escritores que nos ocupan, en dicha representación simbólica de Cuba, un deseo de recuperar a la hembra potente y sensual, madre devota, esposa fiel e hija querida.

DE NACIÓN Y DISCURSOS

Puesto que el presente ensayo pretende identificar las diversas construcciones discursivas de Cuba según se representan en el cuerpo de los personajes femeninos de Hijuelos y Pérez Firmat, y puesto que Cuba no puede entenderse sólo como un espacio geográfico aislado, habría que hacer una revisión del concepto de nación para entender cómo se representa a Cuba en ambas novelas.

La pregunta ¿qué es Cuba? se responde de manera múltiple en los dos textos que vamos a analizar. ¿Es un país, una patria, una idea, una ficción? Los escritores cubanoamericanos, que imprimen en sus textos la tremenda experiencia del exilio, no definen a Cuba como un espacio firme, concreto e inmutable, sino como un espacio que se resiste a cualquier delimitación, haciéndose y rehaciéndose en los terrenos de lo movedizo, lo ficticio, lo abstracto y lo variable. Aunque de hecho existe una representación 
colectiva de la isla construida conforme a un ideario cultural popular entre los exiliados y emigrantes cubanos, Cuba es para el escritor cubanoamericano un espacio de contradicciones donde cohabitan, entre otras cosas, los recuerdos y el presente del exiliado, la esperanza y la fatalidad, la hermosura y el ultraje. Es la historia oficial y la oficiosa, la de otros tiempos pasados y la que se está haciendo desde el centro y los márgenes, desde el espacio literario y mítico. El concepto de nación, que en estos tiempos de posmodernidad y poscolonialismo está perdiendo su antiguo esencialismo, no existe sino dialécticamente entre el individuo y su (imaginada) comunidad, en ese entrópico devenir de la conciencia individual, de la historia y la cultura.

En su famosa conferencia de la Sorbona en 1882, Ernest Renan rechazaba los parámetros de raza, lengua, creencias religiosas y geografía, entre otros, como forjadores del principio espiritual que conforma una determinada nación, definiéndola en oposición a la tiranía del estado y sus instituciones:

\begin{abstract}
A nation is a spiritual principle, the outcome of the profound implications of history; it is a spiritual family not a group determined by the shape of the earth. We have now seen what things are not adequate for the creation of such a spiritual principle, namely, race, language, material interest, religious affinities, geography, and military necessity.... Two things, which in truth are but one, constitute this soul or spiritual principle. One lies in the past, one in the present. One is the possession in common of a rich legacy of memories; the other is present-day consent, the desire to live together, the will to perpetuate the value of the heritage one has received in an undivided form.... The nation, like the individual, is the culmination of a long past of endeavors, sacrifice, and devotion. [La nación es un principio espiritual, resultado de las profundas implicaciones de la historia; es una familia espiritual, no un grupo determinado por la forma de la tierra. Ya hemos visto lo que no es adecuado para la creación de dicho principio espiritual, por ejemplo, la raza, la lengua, el interés material, afinidades religiosas, geografía, y la necesidad militar...Dos cosas, que en realidad son una, constituyen esta alma, este principio espiritual. Una radica en el pasado, otra en el presente. Una es la posesión común de un legado rico de memorias; la otra es el consenso presente, el deseo de vivir juntos, la voluntad de perpetuar el valor del legado que se recibe en forma indivisible... La nación, como el individuo, es la culminación de un largo pasado de esfuerzos, sacrificios y devoción. (Bhabha 18-19)
\end{abstract}

Al emplazar ese principio espiritual tanto en el pasado como en el presente común de los pueblos, Renan nos invita a una interpretación de lo nacional que pone en tela de juicio el imperialismo cultural de un momento histórico concreto. Tal posición teórica parece confirmar que la idea de nación no puede excluir la idea de pasado, por muy abstracta y relativa que ésta sea, y es precisamente la idea de pasado donde la memoria, individual y social, entra en juego. Si Renan dedicaba su estudio al tiempo de formación de las naciones modernas, en el momento histórico que nos ha tocado vivir desde la segunda guerra mundial, con sus constantes diásporas y sus diferencias culturales, hemos de recoger necesariamente esos parámetros de raza, lengua, creencias religiosas y geografía, así como los de género, clase, sexualidad e ideología, para establecer con cierta justicia lo que define, si llega a ser posible, a una nación. 
Homi Bhabha se hace eco de los razonamientos de Renan para dar valor al presente como forma de revisión del pasado mítico:

[T] he present of the people's history, then, is a practice that destroys the constant principles of the national culture that attempt to hark back to a "true" national past, which is often represented in the reified forms of realism and stereotype [El presente de la historia de un pueblo, pues, es una práctica que destruye los principios constantes de la cultura nacional que trata de recordar un pasado nacional ‘verdadero', el cual usualmente se presenta en formas reificadas como el realismo y el estereotipo.] (303)

El pasado de Cuba, la historia mítica, oficial, de la nación cubana, según demuestran los textos cubanoamericanos, no es sino una versión de Cuba. Los escritores cubanoamericanos de segunda generación conservan gran parte de la mitificación romántica que los miembros de la primera generación y de la del uno y medio tienen de Cuba, esa madre patria que les ennoblece y los distingue del norteamericano común. Existe en ellos una lealtad a las raíces cubanas que no está reñida con esa otra lealtad que profesan a los Estados Unidos. Su particular posición cultural les otorga el privilegio de la dualidad, ese carácter étnico del que habla Pérez Firmat: “The ethnic accepts that his patria is not, nor can ever be, his país. And what is more, he is not disturbed by this split. Since identity does not interest him, he does not suffer identity crises. Instead, like the amphibian, he revels in his doubleness [El étnico acepta que su patria no es su país, y que nunca puede serlo. Más aún, a él no le preocupa esa escición. Como no le interesa la identidad, no sufre crisis de identidad. En su lugar, disfruta su dualidad, como un amfibio] ("Trascending Exile..." 5). La literatura de la diáspora cubana muestra una voluntad de revisar la historia mítica de la nación, tanto aquella que se inspira en el recuerdo, mitificado o resentido, como la que emana del espacio político de la isla.

La defensa a ultranza de ese pasado mítico, inmemorial, tal como lo llama Brennan, impide el equilibrio entre la historia, que identifica la nación como estado, y el concepto escurridizo de lo nacional, “something more ancient and nebulous -the 'natio'- a local community, domicile, family, condition of belonging [algo más antiguo y nebuloso -la 'natio'- una comunidad local, domicilio, familia, condición de pertenecer]”. La distinción entre ambos componentes de la idea de nación "is often obscured by nationalists who seek to place their own country in an 'immemorial past' where it's [sic] arbitrariness cannot be questioned [se borra usualmente cuando los nacionalistas tratan de situar a su propio país en un 'pasado immemorial' cuya arbitrariedad no se puede cuestionar]” (45). La nación, pues, no es un concepto unívoco: no es la ideología política que falsamente la identifica el espacio geográfico, ni sólo el epítome de una historia contada por unos u “otros”, ni una ideología transitoria ligada a un territorio. Son los sistemas culturales, en plural y en pasado, los que, en constante dialéctica, dan lugar a la nación en las coordenadas del presente. En su revisión del nacionalismo, Benedict Anderson expone cómo la nación surge como un movimiento de fuerzas contrarias:

If nation states are widely considered to be 'new' and 'historical', the nation states to which they give political expression always loom out of an immemorial past and ... glide into a limitless future. What I am proposing is that Nationalism has to be understood, by aligning it not with self-consciously political ideologies, but with large cultural systems 
that preceded it, out of which -as well as against which-it came into being. [Si los estados naciones se han considerado ampliamente ‘nuevos' e 'históricos', las naciones estados que expresan políticamente siempre surgen de un pasado inmemorial y... se deslizan hacia un futuro sin límites. Lo que propongo es que el Nacionalismo tiene que entenderse en conjunción no con ideologías políticas auto-concientes, sino con sistemas culturales amplios que lo han precedido, y de los cuales, y en contra de los cuales, surge] (19). ${ }^{6}$

Tal sistema de fuerzas contrarias desde el cual se define una nación por lo que no es, siempre frente a otras naciones, incluye, entre otros, un sistema de fuerzas contrarias que también ejerce una fuerte diferenciación: el del género y la sexualidad. De la propia descripción de Anderson de las naciones modernas se desprende la idea de nacionalidad como algo inherente al individuo, igual que su género. Para Anderson la nación es imaginada (ya que hay distintas subjetividades sobre lo que tienen en común los individuos de una nación), es limitada (ha de tener necesariamente fronteras, aun cuando éstas ostenten una mayor o menor flexibilidad), y es comunitaria (pese a las diferencias económicas y sexuales, la nación se siente como algo común, como una camaradería horizontal). ${ }^{7}$ Siguiendo tal razonamiento, la subjetividad que moldea la imaginación, así como la noción de frontera en el caso de las diásporas, y la camaradería entre individuos, han de estar sujetas a una diferenciación añadida: la del género y sexualidad. Porque subjetividad, noción y camaradería no son conceptos unívocos, y para analizar Cuba como patria en el texto literario es menester aplicar ese sistema de diferencias.

Así, la "formación discursiva” con la que Foucault se refiere a la nación ha de enriquecerse con la exploración que propone Bhabha de la "the Janus-faced ambivalence of language itself in the construction of the Janus-faced discourse of the nation [la doble ambivalencia del lenguaje mismo en el discurso doble de la nación]” (3). ${ }^{8}$ La doble cualidad del discurso de la nación, ese juego de contrarios donde confines y centro chocan, confluyen y se redefinen, es necesaria para dar autenticidad a los sistemas culturales que la componen ad infinitum, transplantándola de una manera simbólica a otras naciones, a otros espacios, a otros intersticios. ${ }^{9}$ El discurso de la nación cubana que se realiza desde la coyuntura de la diáspora se halla impregnado de todo un sistema cultural con las infinitas posibilidades que brindan el sincretismo y la doble cultura, así como las que llevan consigo la identidad sexual. La representación de Cuba como mujer en el discurso de Hijuelos y Pérez Firmat se halla circunscrita a la imagen que proyectan estos escritores de lo femenino desde su propia identidad cubanoamericana y masculina.

\section{CUBA: ESPACIO IMAGINARIO}

En la literatura cubanoamericana se reitera la idea de Cuba como espacio ficticio, como un lugar que pertenece al mundo de la imaginación. Ello es algo que tienen en común las literaturas contemporáneas de cualquier diáspora. Esas ‘imaginary homelands, Indias

\footnotetext{
${ }^{6}$ También citado en la introducción de Bhabha de Nation and Narration, 1.

${ }^{7}$ Véase Imagined Communities, 15 y siguientes.

${ }^{8}$ Bhabha toma el concepto de la doble cara de Jano de Tom Narin en The Break-up of Britain. Véase nota 3 de su introducción a Nation and Narration.

${ }^{9}$ Tomo aquí el concepto “interstitiality," desarrollado por Bhabha en "Frontlines/Borderposts”.
} 
of the mind [patrias imaginarias, las Indias de la mente]' de las que habla Salman Rushdie ${ }^{10}$ son de hecho espacios metanacionales donde los exiliados viven su doble cultura y, los cubanos de segunda generación, su sincretismo cultural. "The nostalgia ever present in the Cuban American’s parents generation,” afirma Eliana Rivero, "has given way to a split, hybrid cultural consciousness in the sons and daughters of exile [La omnipresente nostalgia de la generación de los padres de los cubanoamericanos.... Ha dado lugar a una conciencia cultural híbrida en los hijos e hijas del exilio]” (180). ${ }^{11}$ Cada una de las tres generaciones de cubanos exiliados en Estados Unidos después de la revolución de 1959 tiene su propia experiencia cultural, y por ende, de nacionalidad. En Next Year in Cuba, ${ }^{12}$ Pérez Firmat lo explica con agudeza:

If for my father Cuba is a burdensome fact, and if for my children it's an endearing fiction, for one-and-a-halfers like me, the country of my birth is a blend of both fact and fiction. Since my recollections of the island are an indeterminate mix of eyewitness and hearsay, what I know is mixed with what I have been told. My memories merge with others' dreams. [Si para mi padre Cuba fue un hecho pesado, y si para mis hijos es una ficción afectuosa, para los uno y medio como yo, el país natal es una mezcla de hechos y de ficciones. Ya que mis recuerdos de la isla son una mezcla indeterminada de testigos y de chismes, lo que sé está entremezclado con lo que me han dicho. Mis memorias se funden con los sueños de los demás.] (12)

Nacido en Cuba y exiliado a EE.UU. a la edad de once años, Pérez Firmat reparte su identidad cubana entre lo real y lo imaginado, desarmando el concepto esencialista y

${ }^{10}$ Desde su posición de desplazado, Rushdie explica los peligros de conservar el pasado intacto, invulnerable a las transformaciones de la memoria: "It may be that writers in my position, exiles or emigrants or expatriates, are haunted by some sense of loss, some urge to reclaim, to look back, even at the risk of being mutated into pillars of salt. But if we do look back, we must also do so in the knowledge -which gives rise to profound uncertainties- that our physical alienation ... almost inevitably means that we will be not capable of reclaiming precisely the thing that was lost; that we will, in short, create fictions, not actual cities or villages, but invisible ones, imaginary homelands, Indias of the mind" (10).

${ }^{11}$ En su artículo de 1990 “(Re)writing sugarcane memories” Eliana Rivero auguraba el éxito de la literatura cubanoamericana (“... Cuban American authors are eloquently (re)writing themselves into the present panorama of U.S. Hispanic literature -sometimes even into the mainstream discourse ...” 180), viéndose cumplido en el decenio de los noventa con la aparición de otros escritores como Cristina García.

${ }^{12}$ Next Year in Cuba. A Cubano's Coming-of-Age in America es una narración autobiográfica donde Gustavo Pérez Firmat recoge los acontecimientos más relevantes de su vida, desde su infancia en Cuba hasta el presente en Estados Unidos. El libro es un riquísimo documento que aúna su testimonio de exiliado con las reflexiones intelectuales propias del crítico literario. Ya en su concepción del libro, que no quiere limitarse a una mera recopilación de recuerdos, se anuncia una transcendencia de la condición tradicional del exiliado: “Although I will be writing mostly about my life, this isn’t a memoir, for the past is not my destination. Rather than memorious, I intend to be recollective, in both senses of the word: my purpose is not simply to recall the past but also, and primarily, to weave together the different strands of my life as an exile into a design for the present and the future. I write to collect myself, to shape disparate fragments into a portrait that I can recognize and embody" (1213). 
estable de nación al declarar, no sin cierto dolor, su ubicuidad cultural -"Mine is a life in places and a life out of place [Mi vida es una vida en lugares y una vida fuera de lugar]”:

Born in Cuba but made in the U.S.A., I can no longer imagine living outside American culture and the English language. And yet Cuba remains my true home, the place that decisively shaped my character and my values. My life is a delicate balancing act between two countries, two cultures, two languages. Ask me where I belong, in Cuba or in America, and I wouldn't be able to tell you, because I belong to both. [Nacido en Cuba pero hecho en los EE.UU., no puedo ya imaginar vivir fuera de la cultura americana y del inglés. Y aún así Cuba sigue siendo mi verdadero hogar, el lugar que determinó de manera decisiva my personalidad y mis valores. Mi vida es un esfuerzo de constantes balances entre dos países, dos culturas, dos lenguas. Si me preguntan dónde pertenezco, a Cuba o a América, no podría responder porque pertenezco a ambas. ] (Next Year in Cuba $1-2)$

Pasando a las novelas de Oscar Hijuelos, nacido de padres cubanos en suelo norteamericano en 1951, también es la imaginación, además la memoria heredada de su familia y su comunidad lo que modela la idea de Cuba. Con su novela The Mambo Kings Play Songs of Love, Hijuelos recibió el premio Pulitzer en 1989, lo cual significó un gran avance, en términos de propaganda dentro del mercado editorial, para la literatura de emigrantes y exiliados de origen hispánico en EE.UU. ${ }^{13}$ Hijuelos habla de su experiencia como hijo de emigrantes cubanos en Nueva York, describiendo el estigma de tal categoría social y reconociendo su inclinación por la cultura estadounidense, aunque sin renunciar del todo a su herencia cultural cubana: "[W]alking between two worlds, I shifted to one side, though angrily so, and there was much that I did not understand about my life and began writing to discover my feelings about it [ Al caminar entre dos mundos, me viré para un lado, aunque con rabia, y no entendía muchas cosas sobre mi vida y comencé a escribir para descubrir mis sentimientos]" (The Empress of Splendid Season xix). ${ }^{14}$ En sus novelas Hijuelos vierte muchas de sus experiencias personales, centradas siempre en la condición del emigrante y dejando de lado la problemática del exilio, que le es, al menos directamente, ajena. ${ }^{15}$ La idea de Cuba como ficción o mundo imaginario reconocida por Pérez Firmat

13 "It was as if a book written by a Latino finally had placed itself in the center of the dominant cultural discourse, while managing to maintain its distinctive character of marginal otherness" (BruceNovoa 11). Otras excelentes obras de escritores chicanos y puertorriqueños habían visto la luz en editoriales norteamericanas antes de que la novela Mambo Kings ganara el Pulitzer, ésta hizo despertar el interés del público general por el tema latino al recibir tal galardón. Hay que tener en cuenta, sin embargo, que aunque Hijuelos trata en sus novelas temas relacionados con la cultura cubana y examina las vicisitudes del cubano desplazado y de la familia cubana emigrada a los Estados Unidos, su tradición narrativa no obedece a modelos cubanos o hispánicos ni se inspira en ellos.

${ }^{14}$ Para un recuento autobiográfico de Hijuelos, véase la introducción al libro Cool Salsa. Bilingual Poems on Growing Up Latino in the United States, xv-xx.

${ }^{15}$ Aunque de diferentes generaciones, Carolina Hospital relaciona a Óscar Hijuelos con Cristina García, clasificándolos en el grupo que denomina “los atrevidos’ porque ambos se atreven a mezclar en sus narraciones las culturas cubana y norteamericana. Eliana Rivero, pese a que menciona el 
se repite en la obra narrativa de Hijuelos, aunque a éste le separe de su compañero la experiencia del exilio político. Al contrario que Pérez Firmat, Hijuelos no tiene memoria personal de Cuba, pero ambos coinciden en haber heredado los recuerdos de la generación anterior. ${ }^{16}$ Las novelas de Hijuelos, comenta Pérez Firmat, "are told from the perspective of characters who are the American-born children of Cuban parents. For them, Cuba is a fiction, a fantasy island known primarily from the stories of parents and relatives.... The Cuban feeling is a mix of secondhand nostalgia and firsthand curiosity" [se cuentan desde la perspectiva de los personajas que son hijos de padres cubanos, pero nacidos en los Estados Unidos. Para ellos, Cuba es una ficción, una isla fantasía que se conoce mayormente a través de los padres y familiares...] (Life on the Hyphen 136-37).

Algunos críticos reparan en la problemática de la autoridad y la experiencia surgida de esta aparente paradoja que manifiestan los escritores cubanoamericanos, e intentan desmontar el mito de la autenticidad, el cual, tal como apunta O’Reilly Herrera, decide quién tiene autoridad para hablar del exilio y la pérdida (92). La crítica resuelve este problema al proponer una "Cuban(d) presence [presencia cubana]"

\begin{abstract}
which grounds Cuban diasporic identity to an actual place and an idealized (as opposed to imagined) geography and history which is, at once, both present and absent. Absent because the idea of Cuba that most Cuban(d)s nurture and seek to preserve is a lost world, a fragmented void, partially remembered either through the blue cloud of nostalgia or reconstructed through the vicarious imagination of those who either never set a foot on the island, or were not old enough to remember when they left. On the other hand, it is an actual spatial presence, a physical space whose tropical countryside simultaneously functions as an a-temporal and a-historical synecdoche for a spirit, a sensibility, a world view which transcends the ravages of history and human endeavor and ... acts as a kind of nationalistic metaphor [que arraiga la identidad diaspórica cubana a un lugar verdadero y a una geografía e historia idealizadas (y no imaginadas) que están presentes y ausentes a la vez. Ausente porque la idea de Cuba que la mayoría de cubanos desarrollan y tratan de preservar es un mundo perdido, un vacío fragmentado, parcialmente recordado a través de la nube azul de la nostalgia o reconstruido mediante la imaginación vicaria de aquellos que nunca han visitado la isla o que fueron muy pequeños para recordar cuando partieron. Por otro lado, es una presencia de espacio real, un espacio físico cuyo campo tropical funciona simultáneamente como sinécdoque atemporal y ahistórica de un espíritu, una sensibilidad, una visión de mundo que trasciende los destrozos de la historia y del hecho humano... y que actúa como un tipo de metáfora nacionalista]. (93-94)
\end{abstract}

Teniendo en cuenta las mencionadas diferencias entre los dos escritores en sus respectivas experiencias de la diáspora cubana, podemos asociarlos por unos rasgos que le son comunes: Cuba como espacio de la imaginación donde se proyecta, en mayor o menor grado, el doloroso sentimiento de pérdida y donde se recrea la memoria propia o

mérito de Hijuelos dentro del grupo cubanoamericano, no le considera “emigrante aculturado” y de doble identidad, sino "native born Hispanic" (181 y nota 21).

${ }^{16}$ Hijuelos afirma que la memoria de su propia madre, nacida en la isla, es sólo parcialmente propia: “... my mother claims New York as her one an only home, recalling Cuba mainly through childhood memories and her memories of friends” (Cool Salsa xvi). 
la heredada que, como ya se ha dicho, dependen de la posición generacional. Es en ese espacio imaginario donde las nociones de patria, hogar e identidad étnica, y otra más universal, la plenitud existencial, tratan de definirse y resolverse. Ambos novelistas trazan en dicho espacio una geografía femenina que puede entenderse como una personificación de la isla, de modo que Cuba queda definida por una serie de valores, funciones y atributos femeninos construidos desde un ámbito propiamente masculino.

\section{LA ISLA EN EL CUERPo: CUERPOS DE CUBA}

Al principio de este ensayo señalábamos que la identificación de la patria como mujer se ha recreado tradicionalmente en las artes, y cómo la subjetividad masculina ha idealizado la patria al atribuirle ciertas características de la maternidad que considera sagradas. Desde los años sesenta la crítica feminista ha perseguido invertir la posición de la mujer como objeto, a través de la cual ha sido tradicionalmente examinada y definida según parámetros masculinos, y representada a través de un discurso también masculino.

En la introducción de su ya clásica edición crítica The Female Body in Western Culture, Susan Rubin Suleiman argumentaba que el cuerpo femenino es una construcción simbólica que se manifiesta a través del discurso. ${ }^{17}$ La pluma masculina de Hijuelos y Pérez Firmat construye simbólicamente en ciertos personajes femeninos la noción de Cuba como mujer cuyo cuerpo, maternal o sexual, es objeto de deseo. Mediante tal vínculo simbólico creado desde la subjetividad masculina y heterosexual, y determinado por el desplazamiento y el exilio, Cuba como mujer es objeto de múltiples interpretaciones. "The mother's body ... offers the only unchanging territory in an uncertain world [el cuerpo de la madre...ofrece el único territorio inmutable en un mundo incierto]”, señala Jean Franco. ${ }^{18} \mathrm{Y}$ es que la circunstancia del desplazamiento y del exilio contribuye aún más a recrear la patria en un cuerpo maternal, ya que en la imaginación masculina es un lugar seguro, protector y eterno. Para Hijuelos y Pérez Firmat el cuerpo femenino es depositario de una serie de cualidades que contiene el ideario tradicional del patriarcado acerca de lo femenino. Debra Castillo lo expresa en estos términos: "The woman, as the primordial site for the metaphorical generation of discourse, must of necessity embody those unchanging pristine values of permanence, privacy, immobility, and purity as the essential core of national identity [la mujer, como sitio primordial que genera metafóricamente el discurso, necesariamente incorpora esos valores eternos prístinos de permanencia, privacidad, inmobilidad y pureza como el centro esencial de la identidad nacional]” (16). Puesto que la subjetividad masculina se resiste a ver lo que considera suyo -la mujer- como algo mutable, fuera de su control o deshonrado, y puesto que la relación madre-patria es un significante donde los sistemas patriarcales vierten su deseo de permanencia y dominio,

17 "The cultural significance of the female body is not only (not even first and foremost) that of fleshand-blood entity, but that of a symbolic construct. Everything we know about the body . . . exists for us in some sort of discourse" (2).

${ }^{18}$ Citado en Debra Castillo, 17. Castillo emplea el ensayo de Jean Franco "Beyond Ethnocentrism:Gender, Power, and the Third World Intelligentsia" en su magnífico examen de los fundamentos de la crítica feminista latinoamericana Talking Back. Toward a Latin American Feminist Literary Criticism. 
es natural que el discurso nacional de estos escritores se construya sobre modelos femeninos a los que tratan de encapsular y sacralizar.

Veamos ahora cómo el cuerpo de los personajes femeninos de las novelas de Hijuelos y Pérez Firmat muestra su carácter simbólico en la construcción alegórica de la Cuba de su imaginación, su memoria y su subjetividad masculina.

The EMPRESS of the SPLENDID SEASON: La EVA cubana

La novela de Hijuelos The Empress of the Splendid Season narra la vida de Lydia, hija consentida de Don Antonio Colón, hombre de negocios y acalde de una ciudad cubana de provincias. Criada en una familia acomodada de mandato patriarcal, Lydia vive su infancia y adolescencia como la favorita de su padre, dedicada a las distracciones de sociedad y fascinada por la belleza y sensualidad de su cuerpo. La sexualidad de Lydia es reprimida por la ley de decoro social y el machismo de su padre, quien controla su “decencia” a fuerza de correa hasta que, a los veintidós años de edad, esquiva su vigilancia entregándose a un director de orquesta forastero veinte años mayor que ella: “And because she was tired of her father's severity, she opened her legs and, watching the starry sky above, allowed this man to 'take advantage"” [ Y como estaba cansada de la severidad de su padre, abrió las piernas y, mirando el cielo estrellado, dejó que este hombre se aprovechara de ella] (50). La tiranía del padre, "inconsolable about the nature of her character and her proclivity for men [inconsolable con la naturaleza de su personalidad y su inclinación hacia los hombres]" (51), llega a su culminación cuando, al enterarse del hecho, expulsa sin piedad a Lydia de la casa familiar negándole la palabra, así como el apoyo moral y material de por vida. Así, en 1947 la joven se ve obligada a salir de Cuba, marchando a Nueva York en busca del lujo y la vida regalada que conocía por las películas de Hollywood y las frecuentes visitas a su casa de hombres de negocios norteamericanos. Pronto las ensoñaciones de gran dama, basadas en su nivel de vida anterior y en el poder de seducción de su cuerpo, se disipan ante la necesidad de sobrevivir. Como aprendiza en un taller de costura primero, y luego como empleada de limpieza en apartamentos de Manhattan, Lydia trabajará duramente durante el resto de sus días. Hijuelos ha hecho descender a Lydia en la escala social al llegar a EE.UU., y le ha dado como único medio de subsistencia el oficio doméstico que la cubana, sin embargo, nunca llega a considerar como propio de su linaje. Así, sabemos de las humillaciones diarias y las náuseas que hacen vomitar a Lydia “out of a kind of despair, the 'bad nerves' that come from getting down on one's knees to wipe clean a stranger's toilet; from swallowing one's pride, out of necessity [como resultado de un tipo de desesperación, de la nerviosidad de tener que acuclillarse para limpiar un inodoro de algún extraño, de tener que humillarse, por necesidad]” (18). La conciencia de clase alta que Lydia conserva hasta el final de sus días parece poner en tela de juicio el estereotipo de la mujer latina emigrante que llega a Estados Unidos y se gana la vida realizando labores domésticas. Relegadas a labores que no precisan habilidad intelectual, las emigrantes latinas quedan estancadas en un oficio socialmente devaluado que propicia la discriminación. ${ }^{19}$

${ }^{19}$ Es curioso que Hijuelos haya escogido el trabajo de empleada doméstica como única salida laboral para su protagonista, ya que se trata de un terreno ampliamente cultivado por escritoras latinas para 
La joven llegará a contraer matrimonio con un camarero cubano, Raúl, y tendrá dos hijos, Rico y Alicia, representantes de la generación de Hijuelos. Pese a su naturaleza concupiscente, y pese a que desde su llegada a EE.UU. Lydia se halla libre del control paterno, no llega a quebrantar la fidelidad conyugal, imponiéndose a sí misma las normas de la decencia social -y no moral. La infidelidad de Lydia como esposa se desarrolla en su imaginación, puesto que en sus cotidianas ensoñaciones, no deja de recibir placeres sexuales de hombres reales o novelescos que siempre sucumben a su hermosura. Sin embargo, las fantasías de la cubana no están desprovistas de cortejo, de romanticismo ni de galantería; es decir, la suya es una sexualidad salvaje pero ungida del refinamiento de la Cuba de los años treinta y cuarenta. En una ocasión, por dar uno de tantos ejemplos del texto, compra la enciclopedia a un viajante cubano que llama a su puerta no solamente para ayudar a sus hijos en los estudios, sino además porque el hombre tenía un porte elegante, cuidado y apuesto: "[S] he would have bought a whale from him that night, ... she nearly shook and had to contain her desires, to kiss him or to cry on his arms over Raul, or for a kind of bodily loneliness [Le hubiera comprado una ballena esa noche,...casi tuvo que temblar y contener sus deseos de besarlo o de llorar en sus brazos sobre Raúl, o sobre su soledad del cuerpo'” (19). Sirviéndose de elementos, personajes y lenguaje claramente bíblicos, Hijuelos llega a dar a los sueños de Lydia un carácter sacramental, una asociación de inocencia y sexualidad que la identifican como la primigenia Eva: "In the middle of the night she often found herself flying naked over the rooftops of the city, the wind languid and moist over her skin -her whole body delicious with sensations so extreme she would awaken wondering if she had been taken aloft by an angel [En medio de la noche frecuentemente se encontraba volando desnuda sobre los techos de la ciudad, el viento lánguido y húmedo sobre su piel -todo su cuerpo delicioso con sensaciones tan extremas que se despertaba preguntándose si la había ascendido un ángel]” (65).

En su recreación étnica del relato del Génesis bíblico, el escritor se centra en la figura de Eva -y no de Adán, cuyo lugar es menos relevante en la novela- para hacer hincapié en la capacidad creadora de la mujer. En su revisión del mito de la creación, Mieke Bal defiende que la mujer es la primera en existir, puesto que es la primera en recibir significado, en ser diferenciada. ${ }^{20} \mathrm{El}$ acto de dar a la mujer el nombre de Eva (Hawwah, que quiere decir 'mother of all living'), ya confiere a la hembra una cualidad divina, la de creadora, puesto que este nombre propio contiene las letras significativas del nombre de Dios en hebreo:

[T] he woman, as the first representative of a sexually differentiated human being, is the climax of the creation, and the fact that she is appointed as the future creator/provider

revisar el estereotipo de la empleada latina en EE.UU. Las puertorriqueñas Esmeralda Santiago y Judith Ortiz Cofer, la dominicana Julia Álvarez y las chicanas Denise Chávez y Helena María Viramontes han explorado en algunos de sus textos la problemática social, racial y de género que trae consigo tal estereotipo. Para un interesante estudio sociológico de la empleada doméstica mexicana que puede aplicarse a otras latinas, véase Mary Romero, "Life as the Maid's Daughter: An Exploration of the Everyday Boundaries of Race, Class, and Gender".

${ }^{20}$ Mieke Bal lleva a cabo un magnífico estudio filológico de la creación según el Génesis y de la interpretación que de este relato hace San Pablo. "Sexuality, Sin, and Sorrow: The Emergence of Female Character (A Reading of Genesis 1-3)”. 
of 'all living,' may very well be signified in the resemblance between her name and Jahweh's, the consonants $\mathrm{H}$ and $\mathrm{W}$ being the fonetic actant which oppose the creators to the creatures, signified by D and M [de Ha-adam, que significa 'creado de la tierra'] [La mujer, como primera representante del ser humano distinguido sexualmente, es el clímax de la creación, y el hecho de que se le nombra como la futura creadora y proveedora de todo lo vivo, probablemente se representa en la similaridad entre su nombre y el de Jahweh, ya que las consonantes $\mathrm{H}$ y W son las actantes fonéticas que oponen a los creadores de las criaturas, representadas por la D y la M]. (335-36)

Así pues, juega Hijuelos con la idea de la primera mujer, sexuada y curiosa, que sufre de soledad en el paraíso de su imaginación y en el mundo terrenal adonde es simbólicamente expulsada por Don Antonio Colón/Dios. ${ }^{21}$ No es casualidad que el epígrafe de la novela recoja unos versos del Paradise Lost de Milton, "Loneliness is the first thing / which God's eye named not good [La soledad es la primera cosa mala que Dios identificó].” El cuerpo de esta Eva cubana representa a la mujer original, la primera exiliada del paraíso quien, por su necesidad de conocimiento - de su placer sexual en sentido estricto y figuradamente de lo que sobrepasa lo autorizado por el padre- va a recibir el papel de madre de la raza emigrante.

La interpretación de Hijuelos del mito del Génesis muestra una indudable ambivalencia en el hecho de que Lydia es castigada con la expulsión del paraíso (Cuba), pero al mismo tiempo, se le concede la labor divina de crear vida -en términos humanos, de procrear. Afirmando que Dios es más inflexible con el hombre que con la mujer, Bal argumenta que "He explicitly blames him, and indirectly curses him by cursing the earth from which he was taken and to which he shall return [El lo culpa explícitamente, y lo maldice indirectamente al maldecir la tierra de donde vino y a donde regresará]” (333), por lo que se exime a la mujer de la culpa. Lydia encarna, pues, a un ser inocente, curioso y sexualmente definido que, lejos de obedecer ciegamente la voluntad paterna e instigada por su propia condición terrenal (la serpiente, que pone en ella la duda, pertenece al mundo natural y no divino), decide con libertad probar el fruto del árbol de la vida y del conocimiento haciéndose un sujeto libre y, por ende, dueño de su cuerpo, algo que el patriarcado le está vedando. Vida y conocimiento son inseparables, ya que la inmortalidad de la raza humana se produce a partir del conocimiento, el cual, como explica Bal, incluye conocimiento sexual:

[I]t does indeed supply immortality, not to the individual but to the species, . . . Indeed, sexual knowledge, be it morally colored or not, does open your eyes and makes you both die and not die. It makes you live on in the children it allows you to produce. It creates history: the chronological succession of generations in life and death [De hecho, le suple inmortalidad, no al individuo pero a la especie,... De hecho, el conocimiento sexual, ya sea moralmente valorado o no, abre los ojos y hace a uno morir y no morir. Te hace revivir en los hijos que puedes producir. Crea la historia: la sucesión cronológica de las generaciones en la vida y en la muerte.] (329)

\footnotetext{
${ }^{21}$ La relación entre padre e hija en el simbólico paraíso de su vida en Cuba corrobora esta idea. Para comprobar la recreación étnica que Hijuelos hace del relato de la creación y la expulsión del paraíso, 45-51.
} 
Lydia recuerda que durante su infancia en Cuba vivía ajena a la pobreza y al sufrimiento de otras gentes, presentándonos la imagen egocéntrica del ser humano en la inocencia del paraíso, donde no distingue el mal del bien: "Lydia was spoilt and could not, in those days, look much further than the shuttered windows of their stucco-walled house, or feel compassion for the suffering of others [Lydia estaba malcriada y no podía, en esos días, ver más allá de las persianas cerradas de su casa de stucco, o sentir compasión por el sufrimiento de los demás]” (47). Desde el exilio de su paraíso original, ya emancipada del patriarcado, la cubana toma conciencia de los problemas del mundo y asume su sexualidad tomando simbólicamente el papel de madre de la raza emigrante.

No obstante, el paraíso perdido de Lydia no es Cuba como patria. Aunque dice sentirse orgullosa de ser Cubana, no hay en toda la extensión de la novela una apología de lo cubano como algo particular y definido en oposición a otras nacionalidades. Lydia sitúa su origen cubano a la misma altura que otras nacionalidades presentes en los barrios de emigrantes y que la fuerza vocacional de ciertas profesiones. La suya es una defensa de lo puramente humano en la experiencia del desplazado: "In her happy moments she basked in the kind of serenity that comes from knowing, in no uncertain terms, who and what you are -the serenity of belonging without a doubt to something greater than yourself [En sus momentos felices se complacía en un tipo de serenidad que surge del saber ciertamente uno quién y qué es -la serenidad de pertenecer sin duda a algo más grande que sí mismo]” (153). ${ }^{22}$ Los sentimientos de Lydia hacia sus compatriotas cubanos, que llegan a Nueva York años después que ella huyendo de la dictadura castrista, se ciñen a la experiencia humana de la soledad, así como a la adaptación cultural y al desplazamiento social del emigrante. Hijuelos, que siempre evita adentrarse en la política del exilio, sólo pone énfasis en los obstáculos sociales propios del emigrante. Así, Lydia se compadece de sus compatriotas, "[wishing] none of this miseria had ever happened [deseando que ninguna de esa miseria hubiera pasado]”:

The exile's sense of outrage and betrayal, however, was something that she experienced with detachment: her own debacle had taken place in the 1940s and, gradually, her cleaning woman's life had become her destiny.... Still, another part of her, while remembering how lonely she had been when she arrived and how long it took her to even begin to feel right with the world, that part of her felt great sympathy for the New Cubans. [El sentido de coraje y traición del exilio, sin embargo, fue algo que ella sintió con cierta distancia: su propia derrota había ocurrido en los años 40 y, gradualmente, su vida como criada se había vuelto su destino... Todavía, otra parte de ella, la que recordaba lo sola que había estado cuando llegó y lo mucho que le tomó comenzar a sentirse bien en este mundo, esa parte de ella sintió gran simpatía por los nuevos cubanos.] (146-47)

La humanidad de Lydia también está presente en su deseo de posición social y en su vanidad. Si la idea de patria se halla en un nivel espiritual, que hemos identificado como el paraíso perdido, en el nivel material ese mismo paraíso se corresponde con la holgada

\footnotetext{
${ }^{22}$ Resulta interesante que Óscar Hijuelos utilice en una entrevista, mientras habla de sus sentimientos religiosos, la misma expresión que pone en boca de su protagonista de "pertenecer a algo más grande que uno mismo" (52), pues parece relacionar dierectamente el sentimiento de lo cubano con el mundo espiritual. En A.G. Harmon, “A Conversation with Óscar Hijuelos” .
} 
existencia que dejó atrás. La emperatriz de la estación espléndida no puede ser sencillamente mujer, sino una Eva inscrita socialmente en el mundo por sus privilegios de clase y raza "de ahí los títulos de nobleza y alcurnia con que se relaciona a Lydia a lo largo del texo: emperatriz, princesa, reina, gran dama, incluso “cenicienta cubana” (64). Su arrogancia de clase, esa actitud de "otherwordly detachment [distancia como si fuera de otro mundo]" (5), en el barrio de trabajadores donde reside la distancia de sus vecinos, quienes se sorprenden de su presunción social. El orden de prioridades de Lydia, base de sus deseos, sigue unos parámetros humanos que no están politizados por su experiencia étnica. No añora exactamente Cuba, sino su vida de privilegios en la isla: "New York was still the place to prove herself and command the gentlemanly and respectful love of others: that's what she wanted. (Well, that and so many other things: a young body and a virile young man to satisfy her, and beauty to draw attention of every man in a room, and enough money to be driven by the city in a carriage ... [Nueva York todavía era el lugar adecuado para ella probarse a sí misma y suscitar el amor respetuoso y gentil de los demás: eso era lo que ella quería. (Bueno, eso y muchas otras cosas: un cuerpo joven y un hombre viril joven que la satisfaga, y la belleza necesaria para llamar la atención de todos los hombres presentes, y suficiente dinero para pasear por la ciudad en un carruaje]” (213). Persigue, en suma, respeto, belleza, satisfacción sexual y posición social acomodada, todas ellas características inscritas en los ámbitos social y sexual. El cuerpo de la "gran dame of la escoba y los trapos” (190), que rezuma lujuria y vanidad, contrasta de modo irónico con las tediosas labores domésticas a las que se dedica.

Tal arrogancia de clase le trae, además, el resentimiento de sus hijos, a quienes educa "with the notion that they had come from good stock, gente refinada, that they were 'somebodies' [con la idea de que habían venido de alta alcurnia, gente refinada, que eran gente importante]” (34), creando en ellos una lacerante conciencia de clase baja. ${ }^{23}$ Para los americanizados hijos, Cuba no es sino un lugar de fantasía asociado inevitablemente a la sensualidad y el deseo sexual que jamás abandonan a Lydia. El glorioso pasado de Cuba, evocado en ocasiones por Lydia en el cruce de palabras que mantuvo con el actor Errol Flynn cuando era una adolescente, y el fortuito encuentro en Nueva York con James Mason, por ejemplo, confunde a los hijos, quienes perciben "in that moment ... something ravenous in her expression ... a kind of lust or envy...” [en ese momento ... algo voraz en su expresión...un tipo de deseo o envidia...] (339). En los pensamientos de Rico se revela con claridad esta asociación de Cuba con la sexualidad y el erotismo, que en el personaje de Lydia adquiere tintes religiosos:

Lydia may as well have encountered Jesus, for she always blushed in the telling, and that expression in her eyes, that glint of erotic glamour -what else could he call it?- had always confused him, as if talking about such experience was in itself a way of making love. There was something so surrendering about her when she mentioned that kind of event, of seeing "the man who was Robin Hood", and for that matter, whenever she talked about the old Cuba, her Cuba, which was as much as a fantasy as the Land of Oz, as far as the children were concerned.[Era como si Lydia se hubiera encontrado con Jesús, ya

\footnotetext{
${ }^{23}$ En el artículo mencionado, Mary Romero realiza un buena análisis de este estigma de clase baja que marca a los hijos de las empleadas domésticas.
} 
que siempre se sonrojaba al contarlo, y esa expresión en sus ojos, ese destello de encanto erótico -¿cómo podría llamarlo sino eso?- siempre lo había confundido, como si hablar sobre la experiencia en sí fuera una manera de hacer el amor. Había algo como de entrega en ella cuando mencionaba ese tipo de evento, de ver "al hombre que era Robin Hood”, y respecto a eso, cuando hablaba sobre la vieja Cuba, su Cuba, la cual era tan fantasía como la Tierra de Oz, según la perspectiva de los hijos. (339-40)

Sus hijos estereotipan a Lydia desde la perspectiva estadounidense, de modo que no comprenden que una empleada doméstica pueda ser sensual y además pretender que su posición social es acomodada y que sus modales son exquisitos.

En sus dos hijos, Rico y Alicia, cristalizarán respectivamente el deseo social y la sexualidad de Lydia, ya despojados de cubanidad. Gracias a los esfuerzos de la madre, ambos enderezan su adolescencia rebelde y disipada. Rico, con dolorosos prejuicios de clase, será el producto social, cumpliendo el "sueño americano" al convertirse en un afamado psicólogo de Nueva York, con consulta y residencia en Manhattan. Viviendo con lujo y en soledad, Rico sólo conservará su herencia cubana como una anécdota, acompañado siempre de un sentimiento de vacío existencial. Para el joven Rico, Cuba es algo irreal, inventado, y lo rechaza porque es precisamente la causa por la que su madre se sale del estereotipo de empleada doméstica latina. Alicia, por otra parte, de su madre hereda la fuerza femenina. Perdida como Lydia lo estuvo en Cuba, pero en suelo norteamericano, Alicia "contrived the idea that everything in her life was something she had invented, even the family legacy of Cuba [inventó la idea de que todo en su vida era algo que ella se había inventado, hasta el legado de la familia de Cuba]” (186-87). Alicia siente hacia Lydia el rechazo típico del complejo de Electra, de manera que hace a su madre responsable de la castración de la familia. Con despecho, la hija de la cubana se integra en una comuna de hippies y rechaza la maternidad y el matrimonio, calificando a las mujeres de "brainwashed and repressed [reprimidas y con el cerebro lavado]" (182). Curiosamente, el estado de 'inocencia' de Alicia termina en otro interesante pasaje de tono bíblico, donde Hijuelos reescribe la historia del Génesis, esta vez con Alicia en el papel de Eva, y con Lydia representando el árbol del conocimiento, es decir, la conciencia de la sexualidad: mientras Alicia se baña desnuda en el río, sintiéndose poseída por un dios natural, se entrega sexualmente a un veterano de Vietnam que estaba en la orilla para calmar el dolor de su gesto y su mirada. Es la madre, representada por "a sweeping sound like a straw broom over a floor [un sonido amplio como el de una escoba de paja sobre el piso]” (187), quien despierta su conciencia de hembra, advirtiendo su desnudez y, por ende, la fortaleza femenina: "each time the sweeping seemed more imminent, and somehow more eternal, and connected, in some way, to the powerful influences of her mother -'Mommy,' the queen of the forest- whom Alicia imagined lurking behind every tree but never saw [cada vez el sonido era más inminente, y de alguna manera más eterno, y conectado de algún modo a las influencias poderosas de su madre -'Mami', la reina del bosque- a la cual Alicia imaginaba escondida detrás de los árboles y espiando, pero a la que nunca vio” (188). A partir de esta epifanía, en la que identifica a su madre como el Dios protector, la hija de la emigrante asumirá los papeles de esposa y madre fundando una familia norteamericana común. 
El cuerpo de Lydia en la novela de Hijuelos representa sobre todo la hermosura, una hermosura femenina que se resiste a perecer. Su vanidad y lujuria la hacen, sobre todo, humana. Con ello el escritor, lejos de mitificar a Cuba, la humaniza. "Ésta es la tierra más fermosa que ojos humanos vieron”, escribió Colón en su Diario del primer viaje. La simbología de los apellidos evidencia aún más esta idea: Lydia Colón, Señora y viuda de España -país representado por Raúl, que es tremendamente espiritual, y la deja sola-, quien, descendiendo en la escalera social se convierte en "the Spanish cleaning lady [la criada hispana],” conservará su orgullo de casta y raza. Sus deseos de reconocimiento social y de respeto humano la acompañan en tierra extraña, siempre añorando su estado original de belleza y abundancia. Lydia cumple con los papeles tradicionales de madre y esposa, sin dejar de sentirse, en ningún momento de su existencia, hembra potente y hermosa, y no por ello, débil o subyugada, sino dueña de sí, "she was, above all, fuerte y dura [ella era, ante todo, fuerte y dura] " (123). El discurso nacionalista de Hijuelos en el personaje de Lydia se restringe a la evocación de una patria que se pierde al entrar en contacto con el suelo norteamericano, que sobrevive solamente en el recuerdo. El cuerpo de la cubana ha mantenido su dignidad, como una nación hermosa y fuerte pero que está abocada al desgaste y a la extinción al trasladarse a otro espacio. Hijuelos canta a Cuba, pero no la perpetúa en las nuevas generaciones.

Anything But Love: Buscando a Cuba en el Cuerpo de la gringa

Para la composición de su novela Anything But Love, Gustavo Pérez Firmat se ha servido de una gran cantidad de material autobiográfico según se comprueba en su libro anterior Next Year in Cuba, que relata su experiencia personal en EE.UU. como exiliado cubano de la generación del uno y medio. ${ }^{24}$ En ambas obras el autor explora las tribulaciones existenciales del exiliado-ese “yearning for wholeness [deseo de integridad]”y su ansia de integrar "the Cuban condition with a life on the hyphen [la condición cubana con la vida en el guión]” (My Own Private Cuba 229). A diferencia de Pérez Firmat, el protagonista de su novela, Frank Guerra, no ha transcendido el exilio, que consiste, en palabras del crítico, en la nada fácil tarea de "construing Cubanness as an ethnicity rather than a nationality” (235), es decir, en convertir la cubanidad en una identidad transcultural. Guerra, quien obedece al simbolismo de su apellido al vivir en constante lucha interna, es un cubano de mediana edad, autor de libros de texto para la enseñanza de la lengua española, afincado en EE.UU. desde su adolescencia, casado y con una hija en edad escolar. Las primeras páginas de la novela presentan a Frank comunicando a su padre y a su tío la decisión de divorciarse de Marta, también exiliada cubana, para contraer matrimonio con Catherine O’Neal, maestra de su hija Emily, la “americanita of his dreams

\footnotetext{
${ }^{24}$ Dado que Pérez Firmat reflexiona sobre la experiencia del exilio en su obra autobiográfica Next Year in Cuba (1995), y dada la coincidencia de temas y la semejanza en la trayectoria vital del autor y su personaje en la novela Anything But Love, haré constantes referencias a la primera obra a fin de ilustrar mejor la problemática del exilio en su relación con el cuerpo femenino. Las citas de la novela se indicarán simplemente por el número de página, mientras que aquellas tomadas de Next Year in Cuba irán acompañadas también del año de publicación, esto es, 1995.
} 
[la americanita de sus sueños]” (25). ${ }^{25}$ A pesar de las advertencias del clan Guerra, que entiende este paso como una traición a la familia y a la mentalidad cubana, Frank se embarca en esta nueva vida sintiéndose feliz y seguro de que su pasión por Catherine “wasn’t [his] mid-life crisis [no era su crisis de los cuarenta],” sino “[his] mid-life miracle [su milagro de los cuarenta]” (35).

En la primera parte de la novela, “Intimate Grammar”, la voz narradora de Frank, que nos cautiva con sus artes de filólogo, cuenta con lujo de detalles su aventura extraconyugal con Catherine, su convivencia con Marta, y su definitiva resolución de divorcio. La segunda parte, titulada irónicamente "Perfect Love”, narra en tercera persona la turbulenta relación de los nuevos esposos. Es una historia tortuosa en la que las mentiras -o medias verdades- de Catherine y la creciente desconfianza del iluso Frank transforman la inicial promesa de amor perfecto en una situación insostenible. Durante meses la nueva esposa de Frank le cuenta desordenada y enrevesadamente fragmentos de su vida anterior hasta componer la narración completa. Escarnecido y agraviado, Frank llega a la tremenda conclusión de que Catherine no sufrió una violación, según le contara al poco de conocerse, sino que se ha prostituido durante años inducida por un hombre casado vecino de su familia. La voz en primera persona del protagonista vuelve a conducir la historia en la última parte, "Past and Present”, donde la desesperación del cubano llega a su punto álgido. Decide volver con Marta, quien le rechaza, y busca el consejo de su mejor amigo para finalmente regresar a su vida con Catherine, a quien humilla sexualmente en un intento de exorcismo para superar el trauma que le ha creado la relación con ella. Cierra la novela una escena en la casa familiar donde habita una falsa paz, mientras Frank se debate entre sus posibilidades de una nueva vida y su presente con la inescrutable Catherine.

Frank busca en el matrimonio con Catherine el equilibrio de la existencia incompleta e inestable del exiliado que, mientras aguarda el dudoso regreso a la patria, se revuelve entre dos culturas, dos mentalidades, dos lenguas y dos naciones. Para él, su unión con Catherine es el modo idóneo de asentarse en lo norteamericano. El cuerpo de la angloamericana representa, en toda su extensión, a EE.UU., y poseerlo, contenerlo, es lo que Frank ansía para hacer desaparecer la angustia propia de un ser dividido y desarraigado. En Next Year in Cuba, Pérez Fimat declara en un tono deliberadamente misógino: "My version [of poet Walcott's statement that to change your language you must change your life] is more pedestrian: to change your life you must change your wife. This may sound overly flip, but since marrying a woman is like embracing a culture, one of the most efficient ways to embrace America is to embrace an Americana [Mi versión del comentario del poeta Walcott de que 'para cambiar tu lenguaje tienes que cambiar tu vida' es más pedestre: para cambiar tu vida tienes que cambiar de esposa. Esto puede sonar bastante frívolo, pero como casarse con una mujer es como aceptar una cultura, una de las maneras más eficientes de aceptar América es abrazando a una americana] ” (236). El riesgo, no

\footnotetext{
${ }^{25}$ El propio Pérez Firmat encuentra significativa la relación del cubano de clase y raza privilegiadas Desi Arnaz con la norteamericana Lucille Ball, relación que analiza en los tres primeros capítulos de su libro Life on the Hyphen. The Cuban American-Way para interpretar la cultura cubana en Estados Unidos antes de la revolución de 1959.
} 
obstante, es tratar de abolir la cultura propia al abrazar la nueva. El mismo Pérez Firmat habla de esta fase de su experiencia personal:

The grain of truth embedded inside my fantasies was that the relationship with Mary Anne had cultural as well as personal consequences. If I divorced Rosa, the prominence of Cuba in my life would surely diminish.... And yet, I also thought that my life with Mary Anne might give me the opportunity to advance beyond exile, to settle down once and for all. [La verdad dentro de mis fantasías era que la relación con Mary Anne tendría consecuencias culturales como personales. Si me divorciaba de Rosa, la prominencia de Cuba en mi vida seguramente disminuiría... Y sin embargo, también pensé que mi vida con Mary Anne me daría la oportunidad de trascender el exilio, de poder establecerme de una vez por todas.] (My Own Private Cuba 213)

[B]ut by falling in love with Mary Anne, I was turning my back on a lifetime of choices. I wasn't simply wavering between two companions ... but between two cultures, two languages, and two countries. What my family tended to regard as a mid-life crisis, I knew was something deeper and more disturbing -a mid-culture, mid-language, and midhomeland crisis. [Pero al enamorarme de Mary Anne, estaba rechazando toda una vida de opciones. No sólo estaba ambivalente ante dos compañeras...sino entre dos culturas, dos lenguas, y dos países. Lo que mi familia percibió como una crisis personal a los cuarenta, yo entendí como algo más profundo y perturbador -una cultura a medias, un lenguaje a medias, y una crisis de una patria a medias.] (My Own Private Cuba 222)

La novela muestra toda la angustia del exiliado, quien ingenuamente cree que la solución de su conflicto vital es la posesión de un cuerpo norteamericano, es decir, la asimilación completa que sofocaría la herencia cubana. El escritor rompe las ilusiones de Frank porque éste intenta hacer un trueque de nacionalidades y no una transacción esencial donde lo cubano en suelo estadounidense se convertiría en identidad étnica. Castiga incluso más a su personaje al poner en su camino a una mujer impredecible e insondable que le obliga, lo mismo que el exilio, a vivir en la incertidumbre, que es precisamente de lo que trata de huir: "[H]e was scared off by the unknown.... What he wanted above all was safety [Le tenía miedo a lo desconocido...Lo que quería ante todo era la seguridad.]” (89). Pero en última instancia la tragedia de Frank se debe a su propia ofuscación: le ciega el deseo de perfección, que rige su comportamiento obsesivo, su rigor compulsivo por el control y el orden, por hacer de los azares de la vida una perfecta certidumbre. Su necesidad de 'wholeness [sentirse integrado]', típica del exiliado, afecta a su equilibrio personal. No importa tanto que Catherine sea perversa o infame, lo cierto es que la ceguera de Frank le impide conocerla, y la conciencia narrativa, que es también de Frank, impide a los lectores conocer el punto de vista de la norteamericana y por lo tanto, juzgarla con equidad. ${ }^{26}$ Frank

${ }^{26}$ El personaje de Frank recuerda al artista Juan Pablo Castel, protagonista de El túnel de Ernesto Sábato. Ambos hombres, inteligentes y de una formación intelectual notable, se dejan llevar por sus obsesiones y recelos hasta alcanzar extremos violentos -Castel llega a matar a su amada María Iribarne y Guerra castiga a Catherine con un comportamiento sexual perverso. Asimismo, en ambas novelas la conciencia narrativa es de los protagonistas, Castel y Guerra, privándose al lector del punto de vista de María y Catherine. 
toma el cuerpo estadounidense de Catherine como una representación del país, y lo percibe incierto, engañoso, fragmentado y prostituido frente a la seguridad, claridad, solidez y pureza del cuerpo de Cuba que mora en su imaginación -o en su adulterado recuerdo. En todo caso, tanto Catherine como Marta son objetos de deseo para Frank, quien clasifica el cuerpo de ambas según su sistema de valores patriarcal.

Si Hijuelos toma la idea de Cuba de la memoria, heredada de la generación de sus padres, y en su novela The Empress of the Splendid Season ese espacio imaginario aparece inscrito en el cuerpo social y original que es Lydia, en la novela de Pérez Firmat la isla se presenta como dolorosa pérdida cuya memoria ha sido transfigurada por la temprana experiencia del exilio que ha sufrido su protagonista. Aunque se siente completamente cubano, la memoria de Frank no le lleva a recordar detalles ni acontecimientos concretos de Cuba. Adaptado a la forma de vida estadounidense, conoce las diferencias que existen entre esta cultura y la cubana, y siempre, ya inconsciente o conscientemente, defiende su modo cubano de entender la vida. Es más, a Frank no le define de una manera natural el país que le vio nacer, sino más bien la cultura cubana transplantada a suelo estadounidense por la comunidad de exiliados que ha creado su propio espacio en Miami ciñéndose al tiempo del primer éxodo, "Little Havana, a 1950s time-capsule [La Pequeña Habana, una cápsula de tiempo de los años 50]” (110). La isla de Cuba, también en esta novela, se convierte en un espacio imaginario al que Frank se refiere como "my country -a little fantasy island in the Caribbean [mi país- una pequeña isla de fantasía en el Caribe]” (109).

La esposa cubana de Frank, Marta, ocupa metafóricamente esa isla imaginaria. No se describe físicamente su cuerpo en la novela -fascinado por el cuerpo de Catherine, Frank sólo hace referencia a su falta de erotismo $(5,92)$. Sin embargo, la cubana aparece caracterizada como una mujer de naturaleza fuerte, cumplidora de sus labores familiares, disciplinada y, lo más importante, el antídoto contra la incertidumbre que atormenta a Frank, "his shelter from the storm, his sand-bagged sanctuary against uncertainty [su refugio de la tormenta, su santuario como bolsas de arena en contra de la incertidumbre]" (88). Esta descripción de Marta alude a esa idea mítica de Cuba señalada anteriormente: seguridad, claridad, solidez y pureza.

Marta representa a Cuba en relación a un tiempo anquilosado en el ayer y a los reducidos ámbitos del hogar y la familia. Durante treinta años Frank ha tratado de compaginar su esencia cubana en EE.UU. a fin de dar sentido a una existencia en la que los conceptos cubano y americano parecen incompatibles. En su matrimonio con Marta primaba lo cubano, sostenido de modo artificial fuera del tiempo y del espacio reales, mientras que la parte norteamericana era sólo un telón de fondo, unas coordenadas de tiempo y espacio provisionales. Los intentos de Frank para burlar el paradigma del tiempo antes de conocer a Catherine fueron en vano. Con Marta el reclamo de su cubanidad era natural, sintiéndose anclado en la condición de regresar al pasado; en cambio, Catherine le brinda el movimiento, "enter[ing] a world of promise, leaving behind a world of obligation [entrando a un mundo de promesas, dejando atrás un mundo de obligaciones]" (43) y le enseña un concepto nuevo, el futuro, que no forma parte del vocabulario del exiliado: "[T] look ahead, an expression for which there is no good equivalent in Spanish, a language bound to the past like a beast to its burden [Mirar adelante, una expresión para la cual no existe un equivalente en español, una lengua ligada al pasado como la bestia a 
su carga]” (24). ${ }^{27}$ Asimismo, Frank trata de burlar el paradigma espacial a través del hogar y la familia, ámbitos que le ligan a su patria. Cuando entiende que ha renunciado a su familia, prescindiendo del espacio (la casa) en el cual se identifica como cubano, Frank se siente vulnerable y percibe el rechazo de su mujer como un exilio, ya que Marta representa aquí claramente Cuba: "I stared at [Marta] for a minute, then looked around the living room like a man seeing his country for the last time [Miré a Marta por un minuto, luego miré la sala como cuando un hombre ve su país por última vez]” (122). La disolución de la familia atormentará a Frank, que se queja de la falta de comunión de la familia de su esposa norteamericana: “That was the other thing he didn't like. In the family outings he was used to, everybody acted in unison.... Not so with the Thomases, who vacationed like rugged individualists, or perhaps like loners [Esa era otra cosa que no le agradaba. En las excursiones de familia a las que estaba acostumbrado, todos hacían las cosas juntos... Pero no era así con la familia Thomas, pues ellos salían de vacaciones como individualistas toscos, o quizás como solitarios]” (94). Irónicamente Frank va a transmitir a su hija Emily el legado de la separación arrojándola al mismo vacío que tanto trastorna su vida de exiliado, la incertidumbre, ya que la niña tendrá que dividirse entre las vidas de sus padres (56).

La esposa angloamericana de Frank es el modelo de lo estadounidense, el cuerpo político al que desea pertenecer: "[I]n his eyes Catherine was not just a tipa, but an arquetipa, not a pair of legs but a paradigm [Para él, Catherine no era sólo una tipa, sino una arquetipa, no un par de piernas, sino un paradigma]" (42). Es la no-Cuba y es el agente colonizador de su cubanidad. Catherine obedece al apodo de Cat, formado por las iniciales de su nombre de soltera, lo cual hace que los lectores asocien desde el primer momento a la norteamericana con una criatura felina, y por tanto, taimada y enigmática -“Comets are like cats; they have tails and perform only for themselves [Los cometas son como los gatos, tienen rabos pero sólo actúan para ellos mismos]” (15), se dice al inicio de la narración. El retrato de Cat presenta misterio y diferencias -y por lo tanto, atracción: sus rasgos faciales son mezclados y sus ojos de color mudable: "[H]er face was a candy-box assortment of features: Indian cheekbones, a cute pug nose, pouty lips, and eyes color del tiempo [Las facciones de su rostro eran como una caja de dulces variados: pómulos indígenas, una nariz pequeña y delicada, labios rellenos y ojos color del tiempo]” (16); su acento seductor al hablar en español insinúa esa fascinación por 'el otro', que embauca a Frank, y su afición a pintar, medio no lingüístico de comunicar, se opone a la precisión lingüística del filólogo. Frank la define en términos españoles propios de la cultura caribeña: es una “ciclonera” (“a dangerous woman”), no exactamente bella, sino atractiva, y "una flaca engañosa” ("looked slender with clothes and voluptuous without them” 11). El simbolismo trazado entre Cuba como nación y Frank como individuo no parece casual: conoce a Catherine durante la temporada de ciclones, los cuales, según el cubano, son los fenómenos naturales más nefastos: "Cuban history was measured not by revolutions but by hurricanes [la historia de Cuba no se medía por sus revoluciones, sino por sus huracanes]” (10). La edad de Catherine participa en dicho simbolismo como la fuerza

\footnotetext{
${ }^{27}$ Siempre jugando con el lenguaje, Frank primitiviza y animaliza la lengua española y la cultura
} hispánica a fin de llenarse de razones para liberarse del peso de su cubanidad en el exilio. 
natural devastadora e imprevisible: "[S] he could be anywhere from early thirties to early forties, the hurricane season of life [Su edad podría ser entre los treinta hasta los cuarenta, la temporada huracanada de la vida]" (11).

El sexo y la lengua española son, para Frank, dos remedios del exilio porque le aislan del tiempo y del espacio. En la primera fase de su relación con Catherine, Frank se identifica con ella por la experiencia traumática que cada uno de ellos ha vivido: el exilio y la violación, sintiendo que "exile and rape were somehow alike. Once an exile, always an exile. Once a rape victim, always a rape victim. Just as Cat lived in the shadow of the violation, exiles live in the wake of dispossession [el exilio y la violación eran de alguna manera casi lo mismo. Una vez en exilio, siempre en exilio. Una vez violada, siempre violada. Si Cat vivía bajo la sombra de la violación, los exiliados viven en el rastro de la desposesión]” (24). La relación entre la experiencia política y la sexual es clave para interpretar la representación alegórica de la patria perdida. La actividad sexual con la norteamericana coloca a Frank en el presente más puro y le aparta de su realidad despojándole de nacionalidad, cultura e historia: "Rolling around in the worn carpet, we were visiting a place we'd never been, and it felt like home. Everything was new, yet nothing was unfamiliar [Revolcándonos sobre la alfombra desgastada, visitamos un lugar al cual nunca habíamos ido, y se sintió como un hogar. Todo era nuevo, pero nada era desconocido]” (26). El espacio perdido, pues, se sustituye por otro, efímero, pero no politizado, formado por los propios amantes: "The two of us, whoever we were, were gliding on our bodies to some kind of inarticulate paradise, a place without names, languages, borders, lies. For a small eternity, she and I became that place... [Los dos, fuéramos quienes fuéramos, deslizamos nuestros cuerpos hacia un paraíso que no se puede articular, un lugar sin nombres, lenguas, fronteras, mentiras. Durante una pequeña eternidad, ella y yo nos volvimos ese lugar...]” (139).

El lenguaje es el otro medio por el que Frank se sitúa fuera del espacio político norteamericano, alivio de su exilio, vínculo con su cubanidad. Su peculiar tendencia al análisis etimológico de las palabras y de la filosofía del propio lenguaje, hace que el protagonista viva apasionadamente de las diferencias que halla entre el inglés y el español -y dentro de éste, las construcciones y vocablos característicos del español de Cubaseñalando con convicción cuán engañosos son los falsos cognatos y cómo las carencias léxicas de una y otra lengua definen culturalmente a ambas naciones. Ya se ha dicho que Frank define a Cat incluso con términos de la lengua española (ciclonera, flaca engañosa), y cuando le llega el desencanto, en términos filológicos:

Words can be tricky, but at least they don't deceive you. But Catherine's not a word-she's an ellipsis, a dingbat, an inverted question mark.... I've done with her stories- I call them Cat's litter -what I do with sentences: build paradigms, discover regularities. But the obscure syntax of her life defeats me. The more I know, the less I understand. The more details she gives me, the more blurry the overall design. As we say in my trade, I lack a data structure for those informational units. My wife's a crypt, not a script. [Las palabras pueden ser como un truco, pero por lo menos no te engañan. Pero Catherine no es una palabra -es una elipsis, un signo de interrogación invertido, un bate insistente....He hecho con sus cuentos -les llamaré la arena de gatos de Cat- lo que hago con las oraciones: construyo paradigmas, descubro regularidades. Pero la sintaxis oscura de su vida me derrota. Mientras más la conozco, menos la entiendo. Mientras más detalles me provee, 
menos claro es el diseño. Como decimos en mi profesión, me hace falta una estructura de datos para esa unidad de información. Mi esposa es un secreto, no un libreto.] (111)

El dominio lingüístico y cultural de Frank, igual que su dominio del cuerpo de la esposa 'gringa,' no son sino fugaces apropiaciones de lo cubano y lo estadounidense respectivamente. Al final, el protagonista se rendirá a su conciencia de exiliado, identificando a Cuba con su esposa cubana, y así también con la amargura, con la idea de la muerte y con la entrega incondicional a la patria. Cuba, que como isla se define necesariamente por relación al mar, se entiende como "amargura ... one of the sweetest words in the Spanish language. It cradles the sea-el mar-inside it. Like Marta. Like Martyr. Like loving: amar [amargura...una de las palabras más dulces en el idioma español. Acaricia el mar-el marpor dentro. Como Marta. Como mártir. Como amar: amar]” (134). Frank juega de nuevo con el lenguaje para describir el estado de amargura y de intensa entrega del exiliado a una patria que, como el mar, está presente y hace la realidad hermosa.

Pérez Firmat pone de manifiesto en su discurso literario la complejidad del exilio, cuán precario es el equilibrio entre el espacio real y el ficticio, entre la nacionalidad cubana y la cubanidad concebida como identidad étnica. La novela queda en tablas, mostrando la miseria de Frank, quien siente que ni la vida americana ni la cubanoamericana le satisfacen: "The American way: my balls. Life on the Cuban-American hyphen: ni cojones [La vida americana: mis cojones. La vida en el guión cubanoamericano: ni cojones]” (109). Con una peculiar justicia poética, el escritor desestabiliza la idea de claridad o transparencia del cuerpo político norteamericano, representado en Catherine y, al mismo tiempo, el radicalismo del exiliado cubano:

But exile wasn't the surprise; the surprise is still being here thirty years later. Miami wasn't the surprise; the surprise is Seagroves. Americans weren't the surprise; the surprise is Catherine. And the biggest surprise of all is realizing how little I know about my own life, the mystery story of two long islands and the frail bridge between them. $\mathrm{Ni}$ puta idea, as we say. Sometimes you burn your bridges only to discover that there's a fire raging on the other side. [Pero el exilio no fue la sorpresa: la sorpresa es estar todavía aquí treinta años más tarde. Miami no fue la sorpresa; la sorpresa fue Seagroves. Los americanos no fueron la sorpresa; la sorpresa fue Catherine. Y la sorpresa más grande de todas fue darme cuenta lo poco que sé sobre mi propia vida, la historia misteriosa de dos largas islas y el puente frágil entre ambas. Ni puta idea, como decimos. A veces se queman los puentes para descubrir que hay un fuego devorador al otro lado.] (132)

El comportamiento, naturaleza y características de los personajes femeninos analizados, ya directamente, como en el caso de las cubanas, o por oposición, en el caso de la angloamericana Catherine, representan a Cuba en diferentes facetas, positivas o negativas.

A través de su fisonomía o de diversas particularidades de su cuerpo, bien como individuos o en sus papeles de madre, esposa e hija, tales personajes parecen erigirse en alegorías de una Cuba múltiple y diversa -tierra hermosa, desposeída, enajenada, añorada, inalcanzable o perdida. Dichas construcciones alegóricas revelan una concreta mirada sobre Cuba, desde el exilio y desde la perspectiva masculina de la primera generación de cubanoamericanos. Cuba como discurso se emplaza en la memoria étnica y en la 
imaginación: “Exiles live by substitution... Life in exile: memory enhanced by imagination. Like Don Quijote, every exile is an apostle of the imagination, someone who invents a world more amenable to his ambitions and dreams [Los exiliados viven mediante la sustitución... La vida en el exilio: la memoria exaltada por la imaginación. Como Don Quijote, cada exiliado es un apóstol de la imaginación, alquien que inventa un mundo más ameno a sus ambiciones y sueños]" (Pérez Firmat, Next Year in Cuba 82).

Ni el hijo de emigrantes ni el exiliado consiguen una reconciliación con la patria en sus textos. El discurso de la patria de Hijuelos se tiñe de nostalgia por la hembra ausente cuyo cuerpo erótico y potente llega a perecer en suelo norteamericano. El escritor otorga a la protagonista de The Empress of the Splendid Season la cualidad de madre de la raza emigrante y las características femeninas (y por lo tanto cubanas) de la sensualidad, la belleza y el temperamento. En el discurso que hace de la patria Pérez Firmat la nostalgia quiere aliviarse con la negación y con la sustitución, así que el escritor rechaza el cuerpo femenino maternal con que él mismo está representando a Cuba y busca el cuerpo de la angloamericana, un cuerpo violado e imposible de poseer. Tanto Hijuelos como Pérez Firmat construyen asimismo personajes masculinos que no encarnan a Cuba, sino que, en sus papeles de hijos, esposos, amantes o padres, la requieren, la buscan y la añoran. Como sus personajes masculinos, Hijuelos y Pérez Firmat proyectan su deseo de posesión de la tierra madre en un cuerpo femenino que se les escapa y se desvanece.

\section{BiBLIOGRAFÍA}

Anderson, Benedict. Imagined Communities: Reflections on the Origin and Spread of Nationalism. London: Verso and New Left Books, 1983.

Bal, Mieke. "Sexuality, Sin, and Sorrow: The Emergence of Female Character (A Reading of Genesis 1-3).” The Female Body in Western Culture. Susan Rubin Suleiman, ed. Cambridge/London: Harvard University Press, 1985. 317-38.

Bhabha, Homi K. (ed.). Nation and Narration. London/New York: Routledge, 1990. "Frontlines/Borderposts”. Displacements: cultural Identities in Questions. Angelika Bammer, ed. Indiana University Press, 1994. 269-72.

“ DissemiNation: Time, Narrative, and the Margins of the Modern Nation”. Nation and Narration. London/New York: Routledge, 1990. 291-322.

Brennan, Timothy. "The National Longing for Form”. Nation and Narration. London/ New York: Routledge, 1990. 44-70.

Bruce-Novoa, Juan. "Hijuelos’ Mambo Kings: Reading from Divergent Traditions”. Confluencia 10/2 (1995): 11-22.

Castillo, Debra. Talking Back. Toward a Latin American Feminist Literary Criticism. Ithaca/London: Cornell University Press, 1992.

Grewal, Indepal and Caren Kaplan (eds.). Scattered Hegemonies. Postmodernity and Transnational Feminist Practices. Minneapolis/London: University of Minnesota Press, 1994.

Harmon, A.G. “A Conversation with Oscar Hijuelos”. Image. A Journal of the Arts and Religion 22 (1999): 43-57. 
Herrera O’Reilly, C. Andrea. “Cuban(d) Diasporic Conscioussness and the Myth of Authenticity”. Challengung Cultural Practices in Contemporary Postcolonial Societies. Vigo: Universiade de Vigo, 2001. 89-95.

Hijuelos, Óscar. The Empress of the Splendid Season. New York: Harper Collins, 2000. Introduction. Cool Salsa. Bilingual Poems on Growing Up Latino in the United States. Lori M. Carlson, ed. New York: Henry Holt \& Co., 1994. xv-xx.

Hospital, Carolina. Cuban American Writers: Los Atrevidos. Princeton: Linden Lane Press, 1988.

"Los hijos del exilio cubano y su literatura”. Explicación de Textos Literarios 15/ 2 (1986): 103-114.

Narin, Tom. The Break-up of Britain. London: Verso, 1981.

Pérez Firmat, Gustavo. Anything But Love. Houston, TX: Arte Público Press, 2000. My Own Private Cuba. Essays on Cuban Literature and Culture. Boulder, CO: Society of Spanish and Spanish-American Studies, 1999.

Life on the Hyphen. The Cuban-American Way. Austin: University of Texas Press, 1996.

Next Year in Cuba. A Cubano's Coming of Age in America. New York: Anchor Books, 1995.

“Transcending Exile: Cuban-American Literatura Today”. Occasional Paper Series Dialogues. Richard Tardanico, ed. Miami: Florida International University, Latin American and Caribbean Center, 1987. 1-13.

Renan, Ernest. “What is a Nation?” Nation and Narration. London/New York: Routledge, 1990. 8-22.

Rivero, Eliana. S. “(Re)Wrting Sugarcane Memories: Cuban Americans and Literature”. The Americas Review: A Review of Hispanic Literature and Art of the USA. 18/3-4 (1990): 164-82.

Romero, Mary. “Life as the Maid’s Daughter: An Exploration of the Everyday Boundaries of Race, Class, and Gender”. Challenging Fronteras: Structuring Latina and Latino Lives in the U.S. An Anthology of Readings. New York/London: Routledge, 1997. 195-209.

Rumbaut, Rubén. “The Agony of Exile: A Study of the Migration and Adaptation of Indochinese Refugee Adults and Children”. Refugee Children: Theory, Research, and Services. Frederick L. Ahearn, Jr. y Jean L. Athey, eds. Baltimore: Johns Hopkins University Press, 1991. 61.

Rushdie, Salman. “Imaginary Homelands”. Imaginary Homelands. Essays and Criticism 1981-1991. Harmondsworth: Granta/Penguin, 1992. 9-21.

Suleiman, Susan Rubin, ed. The Female Body in Western Culture. Cambridge and London: Harvard University Press, 1985. 